197,500 repeat examinations were carried out, and 147 lung cancers were diagnosed. Eighty-three of the cancers diagnosed at repeat examinations were resectable $(56 \%)$, and 40 of the patients survived four years $(27 \%)$. The survival rate was higher if the patient denied having new chest symptoms $(33 \%)$ than if he had reported them $(16 \%)$ and was higher in those who attended within 28 weeks of the previous attendance $(33 \%)$ than in those for whom the interval was longer $(18 \%)$. For those who attended within 28 weeks without having developed new symptoms the survival rate was $38 \%$.

As in previous studies, the incidence of lung cancer was found to increase rapidly both with age and with the number of cigarettes smoked per day. At an operating cost of $£ 30$ per 100 miniature $x$-ray examinations it was estimated that the cost of identifying a potential four-year survivor fell from $£ 990$ among non-smokers aged 55 years and over to $£ 180$ in men of the same age group smoking 25 or more cigarettes a day. At younger ages ( 45 to 54 years), when a large proportion of the tumours were oat-celled, the survival rate was less satisfactory $(6 \%)$ and the cost of identifying a survivor was many times higher.

That some of the successful results could, indeed, be attributed to the examinations was shown by comparing the total results obtained in examining 41,800 of the men who were resident in the area of the South Metropolitan Cancer Registry and who attended for at least one repeat examination. Of these men $99.5 \%$ were successfully traced up to June 1964, and 197 were found to have developed lung cancer during the course of the survey. One hundred and ten of these cancers were picked up at the routine examinations and 83, missed by the survey, were discovered from the records of the Cancer Registry or from the national records of deaths at Somerset House. For the set as a whole the four-year survival rate was $18 \%$ - a figure that is appreciably higher than the three-year survival rate $(6 \%)$ recorded for all lung cancers that occurred in the area of the Registry as a whole.

These results provide some modest encouragement for the belief that the widespread use of mass radiography may help to reduce the overall mortality from the disease. Prevention remains the best policy, but in its absence it is estimated that 1,000 five-year survivors above the normal 1,400 might be obtained if the 700,000 men aged 55 years and over who smoked 15 or more cigarettes a day were $x$-rayed at sixmonthly intervals.

\section{Calcium Stones in the Kidney}

Until recently the metabolic investigation of patients with renal stones has lagged behind their surgical management. In this issue of the B.M.F. Dr. B. E. C. Nordin and his colleagues at the Medical Research Council's Mineral Metabolism Research Unit at Leeds present important data on two aspects of stone formation.

The general procedure for investigating a stone-bearing patient is now established. As well as the usual radiological and urological studies of the urinary tract the serum calcium and phosphate should be measured repeatedly with the patient in the fasting state and without venous occlusion from the sphygmomanometer cuff when the blood is taken. ${ }^{1}$ The assessment of the daily urinary excretion of calcium is more difficult, since the upper limit of normal is ill-defined. ${ }^{2-4}$ A valuable expression is calcium excretion per $100 \mathrm{ml}$. glomerular filtrate. It may be calculated from urinary calcium $x$ plasma creatinine $\div$ urinary creatinine, ${ }^{5}$ but simpler and useful expressions are urinary calcium $\div$ urinary creatinine ${ }^{6}$ or urinary calcium $\div$ urinary osmolality. ${ }^{7}$

These investigations will allow the separation of patients who form calcium stones into a minority with fasting hypercalcaemia and hypercalciuria, most of whom will prove to have hyperparathyroidism, and the majority with normal serum levels of calcium. Of the latter over two-thirds will also excrete calcium in normal amounts, however judged; but the remainder, predominantly males, will have hypercalciuria without an obvious cause-so-called "idiopathic hypercalciuria." These patients have an increased intestinal absorption of calcium and an increased urinary loss. Both a primary overabsorption of calcium with excess excretion ${ }^{8}$ and a renal tubular defect leading to calcium loss and a secondary rise in absorption ${ }^{9}$ have been proposed as the main defects in these patients.

Dr. M. Peacock and his colleagues ${ }^{10}$ (and at page 729 this week) have produced important evidence that in these patients the gastrointestinal tract is the primary site of the disorder. They suggest that patients with idiopathic hypercalciuria absorb (and excrete) a greater proportion of dietary calcium than normal as the intake of dietary calcium is increased. Detailed study of nine such patients shows that, in the nonfasting state, the serum calcium is very slightly raised, and that they excrete an abnormally large proportion of calcium when a large amount is given by mouth. They therefore advocate a simple calcium-load test for the diagnosis of idiopathic hypercalciuria.

The treatment of this condition centres on attempts to lower the concentration of calcium in the urine. ${ }^{11}$ Thus, either the intake of calcium may be reduced and its intestinal absorption so kept low, or the volume of the urine may be increased by giving large amounts of fluid. Recently it has been shown that the thiazide diuretics reduce the urinary excretion of calcium. ${ }^{12}$ This appears to be due to their action on the renal tubule, since the intestinal absorption of calcium remains unchanged. ${ }^{13}$ Clearly the long-term treatment of patients with these drugs may be beneficial, but it carries the theoretical risk of producing metastatic calcification.

Patients who form calcium stones and yet have no detectable abnormalities of calcium metabolism considerably outnumber all other stone formers. In this group it is likely that the ratio of the concentration of urinary calcium to the concentration of other solutes is a factor controlling the formation of stone. Recently it has been suggested that the excretion of sodium, ${ }^{14}$ magnesium, ${ }^{3}$ and total solute ${ }^{7}$ may all be important in this respect.

Dent, C. E., Brit. med. 7., 1962, 2, 1419.

2 Brit. med. f., 1965, 1, 671.

3 Evans, R. A., Forbes, M. A., Sutton, R. A. L., and Watson, L., Lancet, $1967,2,958$.

Hodgkinson, A., and Pyrah, L. N., Brit. f. Surg., 1958, 46, 10.

5 Peacock, M., and Nordin, B. E. C., F. clin. Path., in press.

- Nordin, B. E. C., Lancet, 1959, 2, 368.

Chambers, R. McK., and Dormandy, T. L., Lancet, 1967, 2, 1378.

Maurice, P F., and Henneman, P. H., Medicine (Baltimore), 1961, 40, 315 .

- 40, 315. P U and Dancaster, C., 7. clin. Endocr., 1959, 19, 658.

10 Peacock, M., Hodgkinson, A., Nordin, B. E. C., Brit. med. F., 1967, 3, 469.
Nassim, J. R., and Higgins, B. A., Brit. med. F., 1965, 1, 675.

11 Nassim, J. R., and Higgins, B. A., Brit. med. F., 1965, 1, 675. 11,351 .

13 Harrison, A. R., and Rose, G. A., Clin. Sci., 1968, 34, 343.

14 Modlin, M., Ann. roy. Coll. Surg. Engl., 1967, 40, 155.

15 Woolf, L. I., Renal Tubular Dysfunction, 1966. Springfield, Illinois.

16 Wrong, O., and Davies, H E. F., Quart. F. Med., 1959, 28, 259. 
A rare but well-recognized cause of renal stunes and nephrocalcinosis is the inherited disorder renal tubular acidosis. $^{15}$ If not clinically evident it may be recognized by failure to acidify the urine after giving ammonium chloride, ${ }^{16}$ and the patient may or may not have acidosis at rest as judged by the plasma bicarbonate. At page $721 \mathrm{Dr}$. M. Cochran and his colleagues report investigations into stone-bearing patients without obvious metabolic abnormalities who failed to attain an acid urine and who appeared to be suffering from pyelonephritis and an acquired renal tubular acidosis. The triad of pyelonephritis, stones, and infected alkaline urine is well known, the stones frequently being phosphatic staghorn calculi and the organisms a species of Proteus. Hitherto the process has been supposed to start with stone formation and the alkalinity of the urine to rest partly on the urea-splitting activity of the organisms.

Dr. Cochran and his colleagues suggest that in some patients, at least, a reinterpretation of this association is necessary. Of 600 stone-bearing patients 24 were found in whom the urine failed to become acid under stress. These patients were compared with 24 otherwise similar patients in whom it did. The authors conclude that in the group whose urine failed to become acid the primary defect was pyelonephritis, producing an acquired renal tubular acidosis. This was insufficient in most cases to produce a resting acidosis, bone disease, or hypokalaemia, but it caused a failure of urinary acidification, a relative decrease in urinary excretion of citrate, and a relative increase in urinary excretion of ammonium, calcium, and possibly phosphate ions. All these would encourage formation of phosphatic stones and infection with organisms favouring an alkaline medium. A vicious circle would be set up, the chronically alkaline urine leading to further stone formation, infection, further renal damage, and impairment of tubular and eventually glomerular function. As with other conditions, such as hypertension, which arise from and lead to renal failure, it is impossible in the established case to be sure of the initial event. But a strong case has been put forward for removing a further group of stone-bearing patients from among those of "unknown aetiology."

\section{Payment of Doctors' Wives}

When the Council of the British Medical Association met on 5 June it debated a number of topics such as customarily engage its attention as the executive arm, meeting at regular intervals throughout the year, of the Representative Body, whose deliberations except for an occasional special purpose are confined to one annual meeting. The next, at Eastbourne, begins next week. At this Annual Representative Meeting a matter will undoubtedly come up for debate which was before the Council for most of its meeting on 5 June. An account of it was not included in the report of the proceedings published in the Supplement last week, but an attempt is made this week at p. 217 to place at least some of it on record. Here the B.M.F. is in a difficulty. The matter concerns the B.M.A. and Medical Management Services. It affects the B.M.A. as a whole as well as many general practitioners. But at various times during the debate statements were made which no prudent person would wish to see put on permanent record. The Council, however, did not hold its meeting in camera. And though several speakers expressed the hope that this or that would not be reported- which was natural when delicate matters are under discussion-the B.M.F. would be failing in its duty to the Council as a whole and to members at large if it left six hours of sometimes impassioned yet open debate entirely unnoticed.

At the Annual Meeting in 1967 the Representative Body passed two resolutions (158 and 159) as follows:

"158. That this Meeting instructs Council to determine the commercial value of the work done in general practice by dependent relatives.

“159. That this Meeting instructs Council to determine immediately the number of dependent relatives working in general practice, their qualifications, and their geographical distribution."

As a result of the Council's meeting on 5 June counsel's advice is now being taken on the implications of implementing Resolutions 158 and 159 of last year's Annual Representative Meeting "in the light of all the correspondence and other records covering the discussions with M.M.S.," and the Chairman of Council is to report on the situation to the Representative Body next week.

From the point of view of the practising doctor the issue at stake is this. Many general practitioners employ their wife (or another dependent relative) in their practice. But, it is claimed, owing to the way joint incomes are taxed these doctors-possibly under a misapprehension-have not been paying their wives a proper market wage. In other words, wives and relatives may be doing a substantial amount of unpaid work for the Health Service. But the argument has been raised that there may be perfectly proper ways of paying dependent relatives a market wage and at the same time increasing the income of the practice. The Representative Body's resolutions last year were intended to start the Council off on a course of exploration of how that might be done. To understand the present impasse it is necessary to know something more of the events leading up to it.

Medical Management Services is a company founded in 1964 by a Bournemouth general practitioner, Dr. G. C. Price, and his wife. Their aim was to find a way for doctors' wives to be paid a fair wage for the work they did in their husbands' practices. M.M.S. proposed that doctors who wished to employ their wives or other relatives should do so through the company rather than directly. The doctor would pay a fee to M.M.S., who would pay the wife directly, and at the same time look after matters such as insurance and pensions. The commercial value of the work done would be professionally assessed and a fair rate paid, which the company would be prepared to justify to the tax authorities. M.M.S. stated that doctors' wives were generally underpaid, and that as a result the expenses calculated for the purposes of the Pool (then in existence) were too low. A survey of work done and wages paid would, said the company, reveal a large sum in expenses which was not being paid.

M.M.S. sent details of the scheme to the B.M.A., which asked its professional advisers in accountancy and taxation to examine the proposals and to advise whether or not the Association should support or commend them. A number of meetings took place over the next two to three years between the B.M.A.'s advisers and Officers and M.M.S. and its advisers; no final decision was reached. At the Annual Representative Meetings of 1965 and 1966 motions were referred to Council asking it to look into the matter of a survey of the expenses incurred in general practice. Meanwhile negotiations on the "charter" had led to the new form of contract priced by the Review Body in its Seventh 